\title{
In Vitro and In Vivo Correlation of Colon-Targeted Compression-Coated Tablets
}

\author{
Siddhartha Maity, ${ }^{1}$ Amit Kundu, ${ }^{2}$ Sanmoy Karmakar, ${ }^{2}$ and Biswanath $\mathrm{Sa}^{1}$ \\ ${ }^{1}$ Division of Pharmaceutics, Department of Pharmaceutical Technology, Jadavpur University, Kolkata 700032, India \\ ${ }^{2}$ Division of Pharmacology, Department of Pharmaceutical Technology, Jadavpur University, Kolkata 700032, India \\ Correspondence should be addressed to Biswanath Sa; biswanathsa2003@yahoo.com
}

Received 27 October 2015; Accepted 17 January 2016

Academic Editor: Jae Hyung Park

Copyright (C) 2016 Siddhartha Maity et al. This is an open access article distributed under the Creative Commons Attribution License, which permits unrestricted use, distribution, and reproduction in any medium, provided the original work is properly cited.

\begin{abstract}
This study was performed to assess and correlate in vitro drug release with in vivo absorption of prednisolone (PDL) from a colon-targeted tablet prepared by compression coating of core tablet. In vivo drug absorption study was conducted using a high performance liquid chromatographic (HPLC) method, which was developed and validated for the estimation of PDL in rabbit plasma. The calibration curve showed linearity in the concentration range of 0.05 to $50 \mu \mathrm{g} / \mathrm{mL}$ with the correlation coefficient $(r)$ of 0.999 . The method was specific and sensitive with the limit of detection (LOD) and lower limit of quantification (LLOQ) of $31.89 \pm 1.10 \mathrm{ng} / \mathrm{mL}$ and $96.63 \pm 3.32 \mathrm{ng} / \mathrm{mL}$, respectively. The extraction recovery (ER) of PDL from three different levels of quality control (QC) samples ranged from $98.18 \%$ to $103.54 \%$. In vitro drug release study revealed that less than $10 \%$ drug was released in $6.34 \mathrm{~h}$ and almost complete $(98.64 \%)$ drug release was achieved in the following $6 \mathrm{~h}$. In vivo drug absorption study demonstrated lower values of $C_{\max }, \mathrm{AUC}_{\text {total }}$, and protracted $T_{\max }$ from compression-coated tablet. The results confirmed the maximum release of drug in the colon while minimizing release in the upper gastrointestinal tract (GIT). An excellent in vitro and in vivo correlation (IVIVC) was also achieved after considering the lag time.
\end{abstract}

\section{Introduction}

In recent years, colon-targeted oral drug delivery systems have been investigated extensively to achieve better therapeutic response of anticancer, anti-inflammatory, steroidal, and anthelmintic drugs, which are used in various colon-related diseases [1]. The most important advantage of colon-targeted drug delivery system is to provide a high concentration of therapeutic agent at the site of action while minimizing premature drug release in the upper gastrointestinal tract (GIT), namely, stomach and small intestine, and thus reducing the emergence of adverse effects to nontarget areas [2]. Different technologies based on site-specific triggering have been developed to drive the drug molecules to the colon bypassing the upper GIT and to provide a sigmoidal drug release pattern involving a longer lag time $\left(T_{\text {lag }}\right)$ followed by burst release in the colon. The approaches include coating with $\mathrm{pH}$-sensitive polymers, time dependent release systems, and compression coating with polysaccharides [3].
Several $\mathrm{pH}$-sensitive microspheres dosage forms for colon targeting of drugs have been reported. $\mathrm{pH}$-sensitive poly(3-hydroxybutyrate) based microspheres blended with cellulose acetate phthalate (CAP) [4] and polyethylene glycol cross-linked chitosan microspheres coated with CAP [5] have been reported to bypass the release of 5-fluorouracil (5-FU), an anticancer drug, in the gastric acidic environment and to provide slow release in intestinal condition. Polyhydroxybutyrate blended with CAP microsphere has also been found to provide prolongation of cytotoxic effect of 5-FU [6].

However, $\mathrm{pH}$-sensitive and time dependent release systems exhibit unpredictable site specificity, respectively, because of large inter- and intrasubject variation and almost similar $\mathrm{pH}$ values of small intestinal and colonic fluids [7] and wide variation in gastric retention time [8]. Among the various technologies, compression-coated systems based on natural polysaccharides appear to be promising because they are degraded by the enzymes produced by the anaerobic microflora of colon $[7,9]$. 
Natural polysaccharides have been used extensively in designing colon-targeted tablet dosage forms because they are biocompatible and biodegradable [10], highly stable, safe, nontoxic, and hydrophilic and fall under the category "generally regarded as safe" (GRAS) [11, 12]. Additionally, chemical modifications impart many important functionalities over the native polysaccharides for diverse application [13]. Frequently, a blend of polysaccharides provides more desirable drug release profile than a single polymer $[14,15]$. Several polysaccharides such as guar gum, pectin, sodium alginate, and locust bean gum which remain undigested in the upper GIT but degrade by the enzymes secreted by colonic microflora have found applications in the formulation of compression-coated tablets $[12,16]$.

It has, however, been reported that the composition of human gut ecosystem may vary depending on the age, geographic provenance, dietary habit, disease, and intake of antibiotics and probiotics [17]. Moreover, degradation of certain polysaccharides like xanthan gum by colonic bacteria is questionable due to rigid structural framework [18-20]. Hence, it is rational to design a colon-targeted tablet by compression coating with polysaccharides that erodes slowly enough to retard premature drug release in the upper GIT and then provides burst release of the drug from the core tablet in the colon in the absence of colonic bacterial enzymes.

Xanthan gum, an exopolysaccharide obtained from Xanthomonas campestris, chemically consists of $\beta, 1-4-\mathrm{D}$-glucose backbone and a trisaccharide side chain consisting of two mannose residues separated by a glucuronic acid, attached with alternate glucose residues. The terminal D-mannose residue may contain a pyruvate group and the mannose closest to the backbone contains an acetyl function [21]. Sustained release of drugs from native xanthan gum tablets is well documented [21,22]. We previously reported that matrix tablets composed of $\mathrm{Ca}^{+2}$ ion cross-linked carboxymethyl xanthan gum retarded the initial release of prednisolone for a considerable period of time, although complete drug release even in $10 \mathrm{~h}$ was not achievable [23]. Subsequently, we developed a compression-coated tablet in which core tablet of prednisolone containing microcrystalline cellulose (MCC, $55 \mathrm{mg}$ ), crospovidone (CP, $9 \mathrm{mg}$ ), trisodium citrate (TSC, $10 \mathrm{mg}$ ), and prednisolone (PDL, $15 \mathrm{mg}$ ) was coated with $225 \mathrm{mg}$ of a blend of carboxymethyl xanthan gum (CMXG) and sodium alginate (SAL) in a ratio of $1.5: 3.5$, and the resulting tablet provided $T_{\text {lag }}$, the time required to release $10 \%$ or less drug, of $6.06 \mathrm{~h}$ followed by a pulse release within $4.36 \mathrm{~h}$, and, thus, the optimized tablet appeared suitable for colon specific delivery of PDL without the intervention of colonic bacterial enzymes in dissolution fluid [24].

Therefore, the objective of this study was to assess and correlate preclinical pharmacokinetic profiles of PDL with in vitro release from the compression-coated tablet. In order to facilitate oral administration of the tablet in rabbit, a minitablet having the same composition of the previously optimized tablet was prepared and was subjected to in vitro drug release study under dynamic $\mathrm{pH}$ shift condition and in vivo drug absorption study on rabbit's model. An HPLC method was developed and validated to estimate the concentration of PDL obtained from rabbit's plasma.

Prednisolone (PDL), a synthetic glucocorticoid, is most widely used in the treatment of human ailment [25], such as rheumatoid arthritis, inflammatory bowel diseases, psoriasis, and asthma [26-28]. It is used for controlling the symptoms/inducing remission in both ulcerative colitis (UC) and Crohn's disease (CD) [29]. In spite of desired pharmacological responses, it also induces a larger number of multifarious adverse effects when absorbed from the upper GIT [30, 31] and hence appears to be a suitable drug for targeting into the colon [32].

\section{Materials and Methods}

2.1. Materials. Prednisolone (PDL) and dexamethasone as internal standard (IS) were obtained from Mepro Pharmaceuticals, Mumbai, India. Carboxymethyl xanthan gum (CMXG) having a degree of substitution 0.8 was synthesized in our laboratory. Sodium alginate (SAL), $\mathrm{CaCl}_{2}$, $2 \mathrm{H}_{2} \mathrm{O}\left(\mathrm{CaCl}_{2}\right)$, microcrystalline cellulose, $\mathrm{PH} 102$ (MCC), polyplasdone $\mathrm{XL}$ (crospovidone, $\mathrm{CP}$ ), trisodium citrate (TSC), magnesium stearate (MS), and trisodium orthophosphate dodecahydrate (TSP) were purchased commercially. Methanol (HPLC-grade) was obtained from Rankem Pvt. Ltd. Dimethyl sulfoxide (DMSO), ethyl acetate (EA), ammonium acetate (AA), formic acid (FA), polyethylene glycol (PEG-400), and EDTA were purchased from Merck Specialties Pvt. Ltd., Mumbai, India. HPLC-grade Milli-Q water was used throughout the study. All other reagents and solvents of analytical grade were used as received.

2.2. Animals. The in vivo absorption study was conducted on 18 adult healthy male New Zealand rabbits weighing $1.5-2.0 \mathrm{Kg}$. The study was carried out as per the standard guidelines of "Committee for the Purpose of Control and Supervision of Experiments on Animals (CPCSEA)," Ministry of Social Justice and Empowerment, Government of India, and was approved by the Institutional Ethics Committee, Department of Pharmaceutical Technology, Jadavpur University, Kolkata (Approved Protocol number AEC/PHARM/1407/2014). Rabbits were acclimatized with $12 \mathrm{~h}$ light and dark cycles for 15 days and were given free access to standard food and water ad libitum. Rabbits were divided into three groups each consisting of six animals $(n=6)$ and were kept in fasted state $24 \mathrm{~h}$ prior to the experiment. Group I animals were given $0.1 \mathrm{~mL}$ of intravenous bolus of PDL $(10 \mathrm{mg} / \mathrm{mL}$ PDL in $50 \% \mathrm{v} / \mathrm{v}$ of PEG-400 in sterile water for injection). Group II and Group III animals received, respectively, an immediate release core tablet and a compressioncoated tablet both containing $5 \mathrm{mg}$ of PDL.

2.3. Preparation of Core and Compression-Coated Tablets. The core and compression-coated tablets were prepared using $1 / 3$ rd of the ingredients used in the formulation of the optimized tablet having a larger size [24]. Initially, immediate release core tablets having a crushing strength of about $4 \mathrm{Kg}$, the composition and physical characteristics of which are shown in Table 1, were prepared by directly compressing 
TABLE 1: Composition and physical characteristics of core tablet.

\begin{tabular}{lc}
\hline Ingredients & Weight (mg) \\
\hline PDL & 5 \\
MCC & 18.33 \\
CP & 3 \\
TSC & 3.33 \\
MS & 0.34 \\
Total & 30 \\
\hline & \\
Thickness (mm) & \\
Friability (\%) & $2.95 \pm 0.06$ \\
Drug content (mg) & $0.89 \%$ \\
Weight variation (\%) & $5.05 \pm 0.25$ \\
\hline
\end{tabular}

TABLE 2: Composition and physical characteristics of compressioncoated tablet.

\begin{tabular}{lc}
\hline Composition of coating material & Weight $(\mathrm{mg})$ \\
\hline $\mathrm{CMXG}$ & 18.75 \\
$\mathrm{SAL}$ & 43.75 \\
$\mathrm{CaCl}_{2}$ & 12.50 \\
Total & 75 \\
\hline \multicolumn{2}{c}{ Physical characteristics of coated tablet } \\
Thickness (mm) & $3.62 \pm 0.04$ \\
Friability (\%) & 0.78 \\
Weight variation (\%) & -3.26 to 2.00 \\
\hline
\end{tabular}

a blend of drug and excipients with $3 \mathrm{~mm}$ punch in a 10station rotary minipress tablet machine (RIMEK, Karnavati Engineering Ltd., Gujarat, India).

Granules, the composition of which is shown in Table 2, were prepared by wet massing a blend of CMXG and SAL with required amount of $\mathrm{CaCl}_{2}$ solution. The resulting damp mass was passed through \#22 BS screen (width of aperture $0.710 \mathrm{~mm}$ ) and dried at $60^{\circ} \mathrm{C}$ to a residual moisture content of $2-4 \%$. The compression-coated tablets having a crushing strength of about $6 \mathrm{Kg}$ were prepared in the following way: core tablet was placed centrally in $40 \%$ of the granules kept in a $5.5 \mathrm{~mm}$ die and remaining $60 \%$ granules were placed over the core tablet and compressed into tablet using a flat face $5.5 \mathrm{~mm}$ punch in a 10-station rotary minipress tablet machine (RIMEK, Karnavati Engineering Ltd., Gujarat, India). Fifty core tablets and compression-coated tablets were prepared in duplicate.

2.3.1. Evaluation of Physical Characteristics of Tablets. The weight variation and friability of both the core and compression-coated tablets were evaluated following the methods as described in Indian Pharmacopoeia [33]. Drug contents of the core tablets were determined as per the method described elsewhere [23].

2.3.2. In Vitro Drug Release Study. In vitro drug release study was performed as per the method described previously [23]. Six compression-coated tablets were placed in $700 \mathrm{~mL} 0.1(\mathrm{M})$ $\mathrm{HCl}$ solution $\left(37 \pm 0.5^{\circ} \mathrm{C}\right)$ of $\mathrm{pH} 1.2$ contained in 6 vessels of
USP-II dissolution rate test apparatus (TDP-06P, Electro Lab, Mumbai, India) and rotated with paddles at $100 \mathrm{rpm}$. The $\mathrm{pH}$ of the solution was increased after $2 \mathrm{~h}$ to 7.4 by adding $200 \mathrm{~mL}$ $0.2(\mathrm{M})$ trisodium orthophosphate dodecahydrate. After an additional $3 \mathrm{~h}$ period, the $\mathrm{pH}$ of the solution was changed to 6.8 by adding $5 \mathrm{~mL} 2(\mathrm{M}) \mathrm{HCl}$. Aliquots were removed at predetermined times and replenished immediately after each withdrawal with the same volume of fresh media maintained at $37^{\circ} \mathrm{C}$. The aliquots following suitable dilution were analyzed at $248 \mathrm{~nm}$ using Microplate Spectrophotometer (Multiskan Go, Thermo Scientific, USA). The amount of PDL released from the tablets was calculated using calibration curves drawn in the respective dissolution medium.

\subsection{Bioanalytical Method Development}

2.4.1. Instrumentation and Chromatographic Conditions. The HPLC system (Shimadzu, Kyoto, Japan) consisted of a LC20AD solvent delivery unit, a SPD-M20A photodiode array detector, and Rheodyne injector with a $100 \mu \mathrm{L}$ loop. Detection and quantification were performed using LC solution. Chromatographic separation was performed isocratically at a flow rate of $1.0 \mathrm{~mL} / \mathrm{min}$ using a Phenomenex C18 column (particle size $5 \mu \mathrm{m} ; 250 \mathrm{~mm} \times 4.6 \mathrm{~mm}$ i.d.; Phenomenex, Torrance, USA) at $25^{\circ} \mathrm{C}$. The mobile phase consisted of methanol and buffer $(5 \mathrm{mM}$ ammonium acetate and $0.1 \%$ formic acid in Milli-Q water, pH 3.0) in a volume ratio of $58: 42.40 \mu \mathrm{L}$ of sample was injected into the loop of injector and the eluted peaks were measured at $245 \mathrm{~nm}$ using UV detector.

2.4.2. Preparation of Stock and Working Solutions. Stock solutions of PDL and IS were prepared at a concentration of $2 \mathrm{mg} / \mathrm{mL}$ in DMSO and were stored at $2-8^{\circ} \mathrm{C}$ until being used. The working stocks of PDL were prepared from $2 \mathrm{mg} / \mathrm{mL}$ stock of PDL in DMSO by diluting the stock solution with $50 \% \mathrm{v} / \mathrm{v}$ DMSO solution in Milli-Q water afresh before use. The working stock $(25.00 \mu \mathrm{g} / \mathrm{mL})$ of IS in ethyl acetate was also prepared from the stock solution of IS in DMSO $(2 \mathrm{mg} / \mathrm{mL})$.

2.4.3. Preparation of Calibration Standards and Quality Control (QC) of Samples. In order to construct calibration curve, eleven calibration points in the analytical ranges from 0.05 to $50.00 \mu \mathrm{g} / \mathrm{mL}$ of PDL with a fixed concentration of IS at $83.33 \mu \mathrm{g} / \mathrm{mL}$ were selected. $10 \mu \mathrm{L}$ aliquot of PDL working solution (spiking solution) was spiked with $90 \mu \mathrm{L}$ of blank plasma and $500 \mu \mathrm{L}$ of IS $(25 \mu \mathrm{g} / \mathrm{mL})$ in ethyl acetate (EA). The samples of spiked plasma were vortexed for $5 \mathrm{~min}$ for complete extraction of PDL and IS in EA fraction, centrifuged (RMI2C, Remi Cooling Centrifuge, Mumbai, India) at $7000 \mathrm{rpm}$ for $10 \mathrm{~min}$ and allowed to stand for $30 \mathrm{~min}$. The supernatant EA fraction was collected carefully and evaporated to dryness under a stream of nitrogen. The residues were reconstituted with $150 \mu \mathrm{L}$ of freshly prepared mobile phase. Finally, the samples were filtered through $0.2 \mu \mathrm{m}$ syringe filter, and $40 \mu \mathrm{L}$ was injected into the HPLC system. Three levels of QC samples at lower, middle, and higher concentration (LQC, MQC, and HQC), for example, 
$0.150 \mu \mathrm{g} / \mathrm{mL}$ (LQC), $20.00 \mu \mathrm{g} / \mathrm{mL}$ (MQC), and $40.00 \mu \mathrm{g} / \mathrm{mL}$ (HQC), were also prepared in a similar way.

2.5. Bioanalytical Method Validation. The method was validated for specificity, linearity, accuracy and precision, extraction recovery, and stability according to the guidelines and protocols of the United States Food and Drug Administration [34].

2.5.1. Specificity. The determination of specificity was performed by comparing the chromatograms of sample containing analyte (PDL) and IS against the blank plasma spiked with IS.

2.5.2. Linearity. The linearity of calibration curve was assessed by eleven different concentrations of analyte (PDL) ranges from 0.05 to $50.00 \mu \mathrm{g} / \mathrm{mL}$ with a constant concentration of IS $(83.33 \mu \mathrm{g} / \mathrm{mL})$ in spiked plasma samples. Peak area ratios for each concentration level of analytes to IS were measured in six replicates $(n=6)$ and the calibration curve was constructed from the least square linear regression analysis. The linearity was represented as correlation coefficient $(r)$.

2.5.3. Accuracy and Precision. To determine the accuracy and precision, three QC samples (LQC, MQC, and HQC) were analysed for three consecutive days. Precision and accuracy were expressed in terms of coefficient of variation (\% CV) and relative error (\% RE), respectively. In case of precision, the values of $\mathrm{CV} \leq 15 \%$ for MQC and HQC and CV $\leq 20 \%$ for LQC are acceptable. Similarly, in case of accuracy, the values of RE $\leq 15 \%$ for MQC and HQC and RE $\leq 20 \%$ for LQC are acceptable [34].

2.5.4. Sensitivity. The limit of detection (LOD) and lower limit of quantification (LLOQ) were determined according to the following equation:

$$
\text { LOD or LLOQ }=\delta\left(\frac{S_{\mathrm{D}}}{S}\right),
$$

where $\delta$ is a constant ( 3.3 for LOD and 10 for LLOQ), $S_{D}$ is the standard deviation of the analytical signal, and $S$ is the slope of the concentration versus response graph.

2.5.5. Extraction Recovery. The extraction recovery (ER) of analyte (PDL) at three different levels of QC samples $(n=6)$ was evaluated by comparing the peak area responses from the plasma samples spiked with analyte before extraction with those from blank plasma samples extracted and spiked with the same concentration of analyte after extraction. Similarly, the extraction recovery for IS was also performed for a particular concentration of $83.33 \mu \mathrm{g} / \mathrm{mL}$.

2.5.6. Stability. Blank plasma, spiked with three different levels of QC samples, namely, LQC $(0.150 \mu \mathrm{g} / \mathrm{mL})$, MQC $(20.00 \mu \mathrm{g} / \mathrm{mL})$, and HQC $(40.00 \mu \mathrm{g} / \mathrm{mL})$, was stored at different conditions: at room temperature for $24 \mathrm{~h}$ for short term, $-20^{\circ} \mathrm{C}$ for one month and 3 months for long term, and 3 cycles for freeze-thaw stability studies. Area under the curves (AUCs) of the three levels of QC samples were measured.

2.6. In Vivo Absorption Study. Blood samples $(0.5 \mathrm{~mL})$ after intravenous (IV) bolus and oral administration of the respective formulations were collected carefully from the rabbit's marginal ear vein at $5,15,30,60,90,120,180$, and $240 \mathrm{~min}$ intervals for Group I, at 5, 15, 30, 60, 120, 180, 240, 300, and 360 min intervals for Group II, and at 5, 15, 30, 60, $120,240,360,420,480,540,600,630,660$, and $720 \mathrm{~min}$ intervals for Group III animals. The samples were collected in $1.5 \mathrm{~mL}$ microcentrifuge tube (Eppendorf, USA) containing $10 \%(\mathrm{w} / \mathrm{v})$ of EDTA solution, immediately centrifuged at $3000 \mathrm{rpm}$ for $5 \mathrm{~min}$ at $15^{\circ} \mathrm{C}$ in a Cold Centrifuge (Heraeus Megafuge 1.0R, Thermo Scientific, USA), and the supernatant plasma layers were separated and stored at $-4^{\circ} \mathrm{C}$ until being used. The pharmacokinetic parameters including maximum plasma concentration $\left(C_{\max }\right)$, the time required to reach $C_{\max }$ $\left(T_{\max }\right)$, and mean residence time (MRT) were calculated using a software package (Kinetica 5.1).

2.7. In Vitro and In Vivo Correlation (IVIVC). In vitro and in vivo correlation (IVIVC) is a predictive mathematical model, which describes the correlation between an in vitro (amount of drug released) and in vivo (amount of drug absorbed) results of a dosage form. Level A correlation is generally described as linear and represents a point-topoint relationship between in vitro drug release and the in vivo absorption of drugs. Level A IVIVC model using deconvolution method [35] has been adopted in this study design. In order to establish the IVIVC, percentage of drug absorbed in the systemic circulation after oral administration of various formulations was calculated based on the following model independent deconvoluted equation [36]:

$$
C(t)=\int_{0}^{t} C_{\delta \text { iv }}(t-u) \cdot \Gamma_{\text {abs-vivo }}(u) \cdot d u,
$$

where $C(t)$ is the plasma concentration after oral administration of different tablets at time $t, C_{\delta \text { iv }}$ represents the plasma concentration after intravenous bolus injection, $\Gamma_{\text {abs-vivo }}$ represents in vivo absorption rate, and $u$ is the variable of integration.

\section{Results and Discussion}

3.1. Preparation, Evaluation, and Drug Release from Compression-Coated Tablet. In order to facilitate animal feeding, minicore $(3 \mathrm{~mm})$ and compression-coated $(5.5 \mathrm{~mm})$ tablets were prepared by $1 / 3 \mathrm{rd}$ reduction in the composition of the larger tablets optimized previously [24]. The immediate release core tablets and compression-coated tablets intended for colon specific delivery of PDL complied with the Pharmacopoeial requirement [34] with respect to weight variation, drug content, and friability (Tables 1 and 2).

In vitro drug release studies were conducted in a condition mimicking the $\mathrm{pH}$ and transit time in GIT. Drug release from the core tablets was rapid and complete within $45 \mathrm{~min}$ 


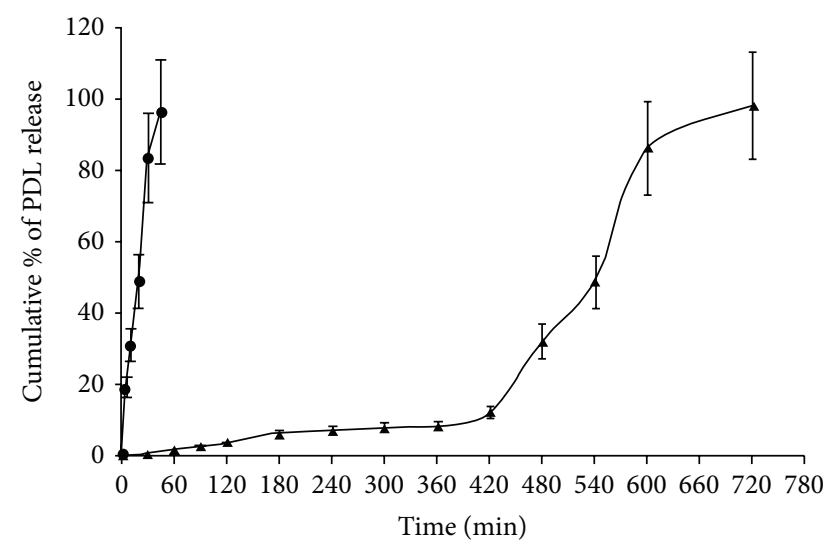

FIGURE 1: In vitro drug release profiles of immediate release core tablet $(\bullet)$ and compression-coated tablet $(\mathbf{\Lambda})$.

(Figure 1) indicating that total amount of drug was released in gastric $\mathrm{pH}$. On the other hand, only $3.9 \%$ and $8.69 \%$ drug were released from the compression-coated tablets, respectively, in $2 \mathrm{~h}$ and $6 \mathrm{~h}$. In order to ascertain that drug release from the minitablet did not differ considerably from the previously optimized tablet having larger size, similarity $\left(f_{2}\right)$ and dissimilarity $\left(f_{1}\right)$ factors were determined and compared [37]. It was found that $f_{2}$ value was $57.03 \pm 1.02$, whereas $f_{1}$ value was $8.92 \pm 0.41$. This indicates that the release profile of tablet in reduced form did not change appreciably.

$T_{\text {lag }}$, defined as the time required to release $10 \%$ or less drug, was found to be $6.34 \mathrm{~h}$. During the next $6 \mathrm{~h}$ period almost complete (98.64\%) drug release was achieved (Figure 1). $T_{\text {rap }}$, the time required for rapid release following the lag time, was calculated by subtracting $T_{\text {lag }}$ from the time required for complete release and was found to be about $6 \mathrm{~h}$. This indicates an effective shielding of PDL release for an initial $6 \mathrm{~h}$ period during which the tablet may be located in the upper GIT and a rapid and complete release within the subsequent $6 \mathrm{~h}$ period when the tablet remains in the colon. Based on the results of in vitro drug release study it may be presumed that compression-coated tablets coated with a blend of $\mathrm{Ca}^{+2}$ ion cross-linked CMXG and SAL $(1.5: 3.5)$ might be suitable for colon targeting of PDL without the need of colonic bacterial enzymes.

3.2. Bioanalytical Method Development and Validation. The HPLC method developed was sufficiently sensitive and suitable for estimation of PDL in rabbit's plasma. The specificity of an analytical method is the ability to differentiate and quantify the analyte (PDL) in the presence of any kind of interfering substances in the sample. The HPLC chromatograms of blank plasma spiked with IS and spiked with IS and PDL have been shown in Figure 2.

The retention time $\left(R_{t}\right)$ of IS and PDL varied from $15.86 \pm 0.15 \mathrm{~min}$ to $15.98 \pm 0.05 \mathrm{~min}$ and $10.91 \pm 0.06 \mathrm{~min}$ to $11.00 \pm 0.026 \mathrm{~min}$, respectively. It was also noted that the chromatogram of PDL was not interfered by the endogenous substances of plasma as most of the interferences were found within $4 \mathrm{~min}$. The calibration curve exhibited excellent
TABLE 3: Summary of the calibration standards at different levels of concentration.

\begin{tabular}{lccc}
\hline $\begin{array}{l}\text { Nominal } \\
\text { concentration } \\
(\mu \mathrm{g} / \mathrm{mL})\end{array}$ & $\begin{array}{c}\text { Observed concentration } \\
(\mu \mathrm{g} / \mathrm{mL})(\text { mean } \pm \mathrm{SD}, \\
n=6)\end{array}$ & $\% \mathrm{CV}$ & $\% \mathrm{RE}$ \\
\hline 50.00 & $50.296 \pm 0.0077$ & 0.02 & 0.59 \\
25.00 & $25.124 \pm 0.0037$ & 0.01 & 0.50 \\
12.50 & $12.559 \pm 0.0031$ & 0.02 & 0.48 \\
6.25 & $6.271 \pm 0.0021$ & 0.03 & 0.34 \\
3.125 & $3.145 \pm 0.0007$ & 0.02 & 0.64 \\
1.56 & $1.568 \pm 0.0011$ & 0.07 & 0.54 \\
0.80 & $0.785 \pm 0.0002$ & 0.02 & -1.82 \\
0.40 & $0.395 \pm 0.0008$ & 0.20 & -1.26 \\
0.20 & $0.198 \pm 0.0000$ & 0.01 & -0.81 \\
0.10 & $0.100 \pm 0.0001$ & 0.13 & 0.02 \\
0.05 & $0.050 \pm 0.0004$ & 0.74 & -0.77 \\
\hline
\end{tabular}

linearity in the concentration range of 0.05 to $50 \mu \mathrm{g} / \mathrm{mL}$ with correlation coefficient of 0.999 . The calibration equation shows the average slope of $0.00693( \pm 0.00001$, range: 0.00692 to 0.00694$)$ and intercept of $-0.000014 \pm 0.000005$. Table 3 showed that all back calculated values of eleven calibration points were excellent in terms of accuracy (\% RE) and precision (\% CV).

The intraday and interday run precision (\% CV) and accuracy (\% RE) of PDL for three levels of QC sample (LQC, MQC, and HQC) ranged from 1.82 to $6.44 \%$ and -0.38 to $5.63 \%$, respectively, and were within the acceptable limits (Table 4).

The limit of detection (LOD) and lower limit of quantification (LLOQ) were found to be, respectively, $31.89 \pm$ $1.10 \mathrm{ng} / \mathrm{mL}$ and $96.63 \pm 3.32 \mathrm{ng} / \mathrm{mL}$ indicating adequate sensitivity of the method for pharmacokinetic study. Moreover, the mean recoveries of PDL at LQC $(0.150 \mu \mathrm{g} / \mathrm{mL})$, MQC $(20.00 \mu \mathrm{g} / \mathrm{mL})$, and HQC $(40.00 \mu \mathrm{g} / \mathrm{mL})$ samples were, respectively, $100.50 \pm 1.34 \%$, $98.22 \pm 2.36 \%$, and $103.77 \pm$ $8.26 \%$. The mean recovery of IS was $102.79 \pm 3.79 \%$ of the concentration used in the assay procedure. Finally, the \% CV and \% RE under short term and long term stability studies varied from 1.67 to $7.30 \%$ and -0.56 to $4.14 \%$, respectively, and were within the acceptable limits (Table 5).

3.3. In Vivo Drug Absorption Study. Intravenous bolus injection of PDL was given in Group I animals to obtain data for in vitro and in vivo correlation (IVIVC). Immediate release core tablets and compression-coated tablets each containing $5 \mathrm{mg}$ of PDL were given orally to Group II and Group III animals, respectively. The plasma concentration time profiles obtained following administration of the drug in different dosage forms are shown in Figure 3, and in vivo absorption parameters are depicted in Table 6.

The first sign of appearance of PDL in plasma in a concentration of $515.65 \pm 4.48 \mathrm{ng} / \mathrm{mL}$ was recorded within 5 min following the administration of core tablets. The peak plasma concentration $\left(C_{\max }\right)$ and the time $\left(T_{\max }\right)$ required 


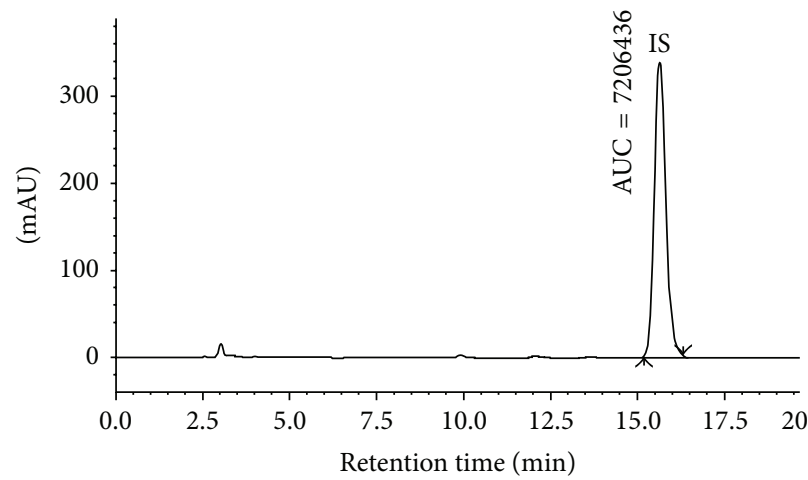

(a)

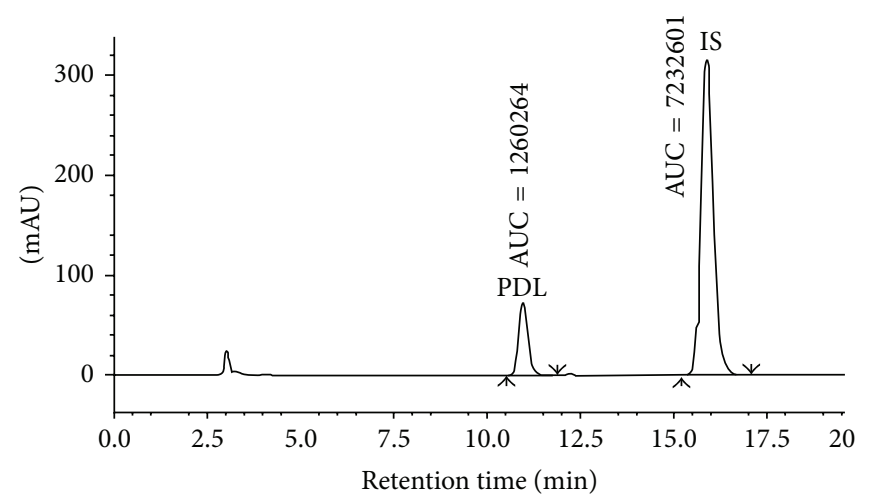

(b)

Figure 2: HPLC chromatogram of (a) plasma spiked with IS $(83.33 \mu \mathrm{g} / \mathrm{mL}$ ) and (b) plasma spiked with PDL (25.00 $\mu \mathrm{g} / \mathrm{mL})$ and IS $(83.33 \mu \mathrm{g} / \mathrm{mL})$.

TABLe 4: Summary of the intraday $(n=3)$ and interday $(n=9)$ precision (\% CV) and accuracy (\% RE) of the three levels of quality control (QC) samples.

\begin{tabular}{lccc}
\hline $\begin{array}{l}\text { Nominal } \\
\text { concentration } \\
(\mu \mathrm{g} / \mathrm{mL})\end{array}$ & $\begin{array}{c}\text { Mean observed } \\
\text { concentration } \\
(\mu \mathrm{g} / \mathrm{mL})\end{array}$ & \% CV & $\% \mathrm{RE}$ \\
\hline $\begin{array}{l}\text { 1st day }(n=3) \\
0.150\end{array}$ & $0.151 \pm 0.0028$ & 1.85 & -0.38 \\
20.00 & $19.45 \pm 0.48$ & 2.48 & 2.73 \\
40.00 & $38.10 \pm 2.41$ & 6.31 & 4.76 \\
2nd day $(n=3)$ & $0.151 \pm 0.0028$ & 1.83 & -0.47 \\
0.150 & $19.53 \pm 0.75$ & 3.83 & 2.33 \\
20.00 & $40.46 \pm 1.46$ & 3.60 & -1.15 \\
40.00 & & & \\
3rd day $(n=3)$ & $0.151 \pm 0.0038$ & 2.54 & -0.68 \\
0.150 & $18.87 \pm 1.11$ & 5.88 & 5.63 \\
20.00 & $38.78 \pm 2.50$ & 6.44 & 3.05 \\
40.00 & & & \\
Interday $(n=9)$ & $0.151 \pm 0.0027$ & 1.82 & -0.51 \\
0.150 & $19.29 \pm 0.78$ & 4.03 & 3.56 \\
20.00 & $39.11 \pm 2.15$ & 5.51 & 2.22 \\
40.00 & & & \\
\hline
\end{tabular}

to reach $C_{\max }$ were, respectively, $1172.28 \pm 22.98 \mathrm{ng} / \mathrm{mL}$ and $60 \mathrm{~min}$. The drug concentration in plasma declined to $114.92 \pm 6.28 \mathrm{ng} / \mathrm{mL}$ at the end of $5 \mathrm{~h}$. On oral administration of the compression-coated tablets, quantifiable amount of PDL $(100.42 \pm 2.81 \mathrm{ng} / \mathrm{mL})$ in plasma was found at $6 \mathrm{~h}$. The plasma drug concentration increased slowly and $C_{\max }$ of $245.40 \pm 10.42 \mathrm{ng} / \mathrm{mL}$ was reached at $10 \mathrm{~h}\left(T_{\max }\right)$ following which concentration declined and reached a level of $109.35 \pm$ $4.29 \mathrm{ng} / \mathrm{mL}$ after $12 \mathrm{~h}$. The results indicated that while PDL was rapidly absorbed from the stomach from the core tablets, compression-coated tablets released very small amount of drug in upper GIT within $6 \mathrm{~h}$. This correlates well with the in
TABLE 5: Summary of the short term and long term stability study data in three different levels of QC samples.

\begin{tabular}{|c|c|c|c|}
\hline $\begin{array}{l}\text { Nominal concentration } \\
(\mu \mathrm{g} / \mathrm{mL})\end{array}$ & $\begin{array}{l}\text { Mean observed } \\
\text { concentration } \\
(\mu \mathrm{g} / \mathrm{mL})\end{array}$ & $\% \mathrm{CV}$ & $\% \mathrm{RE}$ \\
\hline \multicolumn{4}{|l|}{$\begin{array}{l}3 \text { freeze/thaw cycles } \\
(n=6)\end{array}$} \\
\hline 0.150 & $0.144 \pm 0.01$ & 7.30 & 4.14 \\
\hline 20.00 & $20.11 \pm 0.81$ & 4.02 & -0.56 \\
\hline 40.00 & $37.93 \pm 2.03$ & 5.36 & 5.17 \\
\hline \multicolumn{4}{|l|}{$\begin{array}{l}\text { Room temperature at } \\
24 \mathrm{~h}(n=6)\end{array}$} \\
\hline 0.150 & $0.148 \pm 0.0073$ & 4.91 & 1.11 \\
\hline 20.00 & $19.56 \pm 1.33$ & 6.80 & 2.19 \\
\hline 40.00 & $40.80 \pm 2.47$ & 6.06 & -1.99 \\
\hline \multicolumn{4}{|l|}{1 month at $-20^{\circ} \mathrm{C}(n=6)$} \\
\hline 0.150 & $0.153 \pm 0.0026$ & 1.67 & -2.05 \\
\hline 20.00 & $19.23 \pm 1.33$ & 6.91 & 3.83 \\
\hline 40.00 & $39.32 \pm 1.73$ & 4.41 & 1.69 \\
\hline \multicolumn{4}{|l|}{$\begin{array}{l}3 \text { months at }-20^{\circ} \mathrm{C} \\
(n=6)\end{array}$} \\
\hline 0.150 & $0.145 \pm 0.0046$ & 3.13 & 3.12 \\
\hline 20.00 & $19.74 \pm 0.93$ & 4.71 & 1.31 \\
\hline 40.00 & $38.59 \pm 1.45$ & 3.75 & 3.53 \\
\hline
\end{tabular}

vitro drug release where the drug tended to increase rapidly only after $6 \mathrm{~h}$ and almost complete drug release occurred within $12 \mathrm{~h}$. Comparison of $\mathrm{AUC}_{\text {total }}$ values revealed that availability of the drug in systemic circulation from the compression-coated tablets was less than that from the core tablet. This was due to difference in anatomical region of drug release [38]. Compression-coated tablets released the drug in the colon as evident from considerable delay in the appearance of the drug in the plasma. Lower $\mathrm{AUC}_{\text {total }}$ value is an indication of reduced drug absorption from the limited absorptive surface of colon [39]. MRT of compression-coated 
TABLE 6: In vivo absorption parameters of PDL from various dosage form.

\begin{tabular}{lccr}
\hline Parameters & Intravenous (IV) & Core tablet & Compression-coated tablet \\
\hline$C_{\max }(\mathrm{ng} / \mathrm{mL})$ & $1624.29 \pm 15.22$ & $1172.28 \pm 22.98$ & $245.40 \pm 10.42$ \\
$T_{\max }(\min )$ & 5 & 60 & 600 \\
$\mathrm{AUC}$ & $104537 \pm 1292.80$ & $146075 \pm 4133.50$ & $83926.37 \pm 1469.03$ \\
MRT $(\min )$ & $130.05 \pm 2.25$ & $138.33 \pm 5.74$ & $572.33 \pm 7.90$ \\
\hline
\end{tabular}

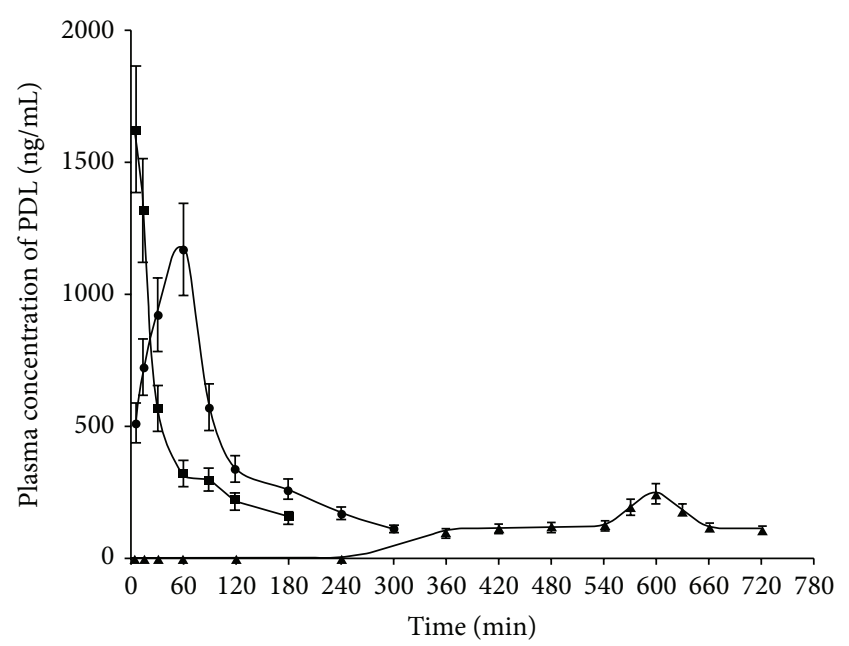

FIgURE 3: Plasma concentration versus time profiles of PDL obtained after oral administration of intravenous (IV) bolus administration (घ), immediate release core tablet $(\bullet)$, and colon-targeted compression-coated tablet $(\mathbf{\Lambda})$.

tablets increased about 4 times in comparison to the core tablets suggesting that compression-coated tablet remained in the GIT for a prolonged period and did not expose the enclosed core tablet until it reached the colon.

3.4. In Vitro and In Vivo Correlation (IVIVC). To assess the correlation between in vitro drug release and in vivo drug absorption data, IVIVC study was carried out using immediate release core tablet and colon-targeted compression-coated tablet. When the cumulative percentage of drug released in vitro from immediate release core tablet was plotted against the percentage of drug absorbed in vivo, a good linear correlation (0.997) was observed (Figure 4).

In case of compression-coated tablet, when the cumulative percentage of drug released was plotted against the percentage of drug absorbed in vivo, a poor correlation (0.842) was observed. However, a good correlation (0.992) was observed when the cumulative percentage of drug released in vitro versus percentage of drug absorbed in vivo was plotted after considering the lag time of $360 \mathrm{~min}$. Moreover, the IVIVC of colon-targeted compression-coated tablet appeared to be a hockey-stick curve that corresponds to nonlinear characteristics of drug release, and drug absorbed from the compression-coated tablet indicates that the mixed function of drug dissolution and permeation through colonic mucosa is the rate limiting step for drug absorption [40].

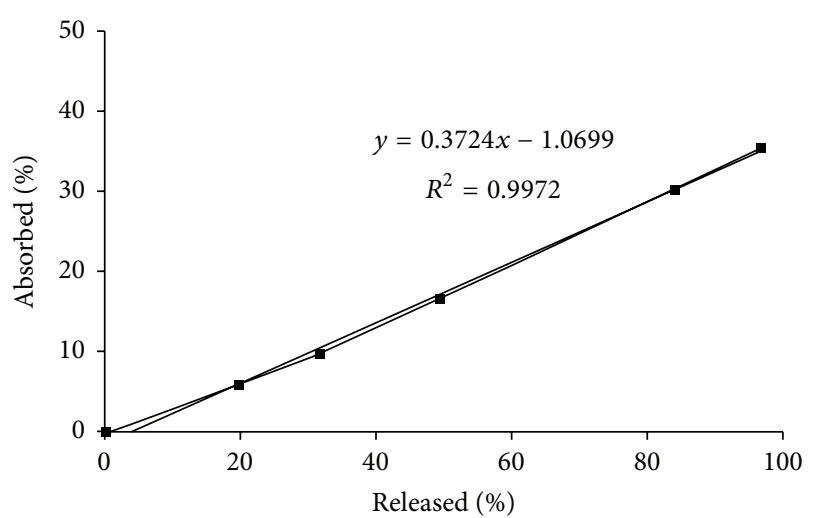

(a)

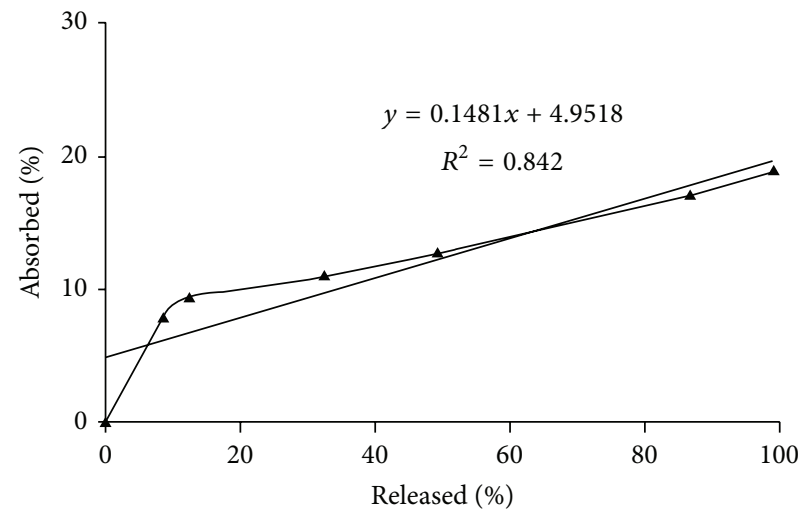

(b)

FIGURE 4: In vitro and in vivo correlation (IVIVC) of (a) immediate release core tablet and (b) colon-targeted compression-coated tablet.

\section{Conclusion}

The results of this study indicated that in vitro release of PDL from the mini-compression-coated tablets was less than $10 \%$ in $6 \mathrm{~h}$ during which the tablets are supposed to be located in upper GIT and complete release was achieved in the following $6 \mathrm{~h}$ in the absence of colonic fluid. In vivo preclinical pharmacokinetic parameters determined by the validated HPLC method reflected the same pattern wherein the plasma concentration was considerably less in $6 \mathrm{~h}$ period and reached a maximum value in $10 \mathrm{~h}$. The lower values of $C_{\max }, \mathrm{AUC}_{\text {total }}$, and protracted $T_{\max }$ in comparison to immediate release tablet indicated that PDL was released in the colonic region of rabbit with minimal drug release in the upper GIT from the compression-coated tablet. A good level A in vitro and in vivo correlation (IVIVC) was also achieved after the lag time 
of drug release in vitro and absorption in vivo. It may be concluded that a blend of natural and modified polysaccharides such as SAL and CMXG both cross-linked with $\mathrm{Ca}^{+2}$ ion to an optimum extent could be a suitable coating material for the development of colon-targeted tablets of PDL.

\section{Conflict of Interests}

The authors declare that there is no conflict of interests regarding the publication of this paper.

\section{Acknowledgment}

One of the authors (S. Maity) wishes to express thanks to the Council of Scientific and Industrial Research, New Delhi, India, for the financial support as CSIR-SRF (Grant no. 9/96 (0727)2K12/EMR-1).

\section{References}

[1] M. L. Zema, M. D. Del Curto, A. Foppoli, and A. Gazzaniga, "Oral colon delivery of insulin with the aid of functional adjuvants," Advanced Drug Delivery Reviews, vol. 64, no. 6, pp. 540-556, 2012.

[2] V. R. Sinha, B. R. Mittal, and R. Kumria, "In vivo evaluation of time and site of disintegration of polysaccharide tablet prepared for colon-specific drug delivery," International Journal of Pharmaceutics, vol. 289, no. 1-2, pp. 79-85, 2005.

[3] M. K. Chourasia and S. K. Jain, "Polysaccharides for colon targeted drug delivery," Drug Delivery, vol. 11, no. 2, pp. 129-148, 2004.

[4] V. R. Sinha and R. Kumria, "Microbially triggered drug delivery to the colon," European Journal of Pharmaceutical Sciences, vol. 18, no. 1, pp. 3-18, 2003.

[5] K. Chaturvedi, A. R. Kulkarni, and T. M. Aminabhavi, "Blend microspheres of poly(3-hydroxybutyrate) and cellulose acetate phthalate for colon delivery of 5-fluorouracil," Industrial and Engineering Chemistry Research, vol. 50, no. 18, pp. 10414-10423, 2011.

[6] K. Ganguly, T. M. Aminabhavi, and A. R. Kulkarni, "Colon targeting of 5-fluorouracil using polyethylene glycol cross-linked chitosan microspheres enteric coated with cellulose acetate phthalate," Industrial and Engineering Chemistry Research, vol. 50, no. 21, pp. 11797-11807, 2011.

[7] K. Chaturvedi, S. K. Tripathi, A. R. Kulkarni, and T. M. Aminabhavi, "Cytotoxicity and antitumour activity of 5-fluorouracilloaded polyhydroxybutyrate and cellulose acetate phthalate blend microspheres," Journal of Microencapsulation, vol. 30, no. 4, pp. 356-368, 2013.

[8] L. Yang, J. S. Chu, and J. A. Fix, "Colon-specific drug delivery: new approaches and in vitro/in vivo evaluation," International Journal of Pharmaceutics, vol. 235, no. 1-2, pp. 1-15, 2002.

[9] B. Bharaniraja, K. Jayaram Kumar, C. M. Prasad, and A. K. Sen, "Modified katira gum for colon targeted drug delivery," Journal of Applied Polymer Science, vol. 119, no. 5, pp. 2644-2651, 2011.

[10] A. G. Sullad, L. S. Manjeshwar, and T. M. Aminabhavi, "Microspheres of carboxymethyl guar gum for in vitro release of abacavir sulfate: preparation and characterization," Journal of Applied Polymer Science, vol. 122, no. 1, pp. 452-460, 2011.
[11] L. Pachuau and B. Mazumder, "Evaluation of Albizia procera gum as compression coating material for colonic delivery of budesonide," International Journal of Biological Macromolecules, vol. 61, pp. 333-339, 2013.

[12] V. R. Sinha and R. Kumria, "Polysaccharide matrices for microbially triggered drug delivery to the colon," Drug Development and Industrial Pharmacy, vol. 30, no. 2, pp. 143-150, 2004.

[13] P. G. Yeole, U. C. Galgatte, I. B. Babla, and P. D. Nakhat, "Design and evaluation of Xanthan gum-based sustained release matrix tablets of diclofenac sodium," Indian Journal of Pharmaceutical Sciences, vol. 68, no. 2, pp. 185-189, 2006.

[14] S. C. Jagdale, S. A. Patil, and B. S. Kuchekar, "Design, development and evaluation of floating tablets of tapentadol hydrochloride using chitosan," Asian Journal of Pharmaceutical and Clinical Research, vol. 5, no. 4, pp. 163-168, 2012.

[15] M. M. Meshali and K. E. Gabr, "Effect of interpolymer complex formation of chitosan with pectin or acacia on the release behaviour of chlorpromazine $\mathrm{HCl}$," International Journal of Pharmaceutics, vol. 89, no. 3, pp. 177-181, 1993.

[16] S. L. Kosaraju, "Colon targeted delivery systems: review of polysaccharides for encapsulation and delivery," Critical Reviews in Food Science and Nutrition, vol. 45, no. 4, pp. 251258, 2005.

[17] J.-C. Lagier, M. Million, P. Hugon, F. Armougom, and D. Raoult, "Human gut microbiota: repertoire and variations," Frontiers in Cellular and Infection Microbiology, vol. 2, no. 136, pp. 1-19, 2012.

[18] J. Daly, J. Tomlin, and N. W. Read, "The effect of feeding xanthan gum on colonic function in man: correlation with in vitro determinants of bacterial breakdown," British Journal of Nutrition, vol. 69, no. 3, pp. 897-902, 1993.

[19] A. M. Oprea, M. T. Nistor, L. Profire, M. I. Popa, C. E. Lupusoru, and C. Vasile, "Evaluation of the controlled release ability of theophylline from xanthan/chondroitin sulfate hydrogels," Journal of Biomaterials and Nanobiotechnology, vol. 4, no. 2, pp. 123-131, 2013.

[20] T. Ramasamy, U. D. S. Kandhasami, H. Ruttala, and S. Shanmugam, "Formulation and evaluation of xanthan gum based aceclofenac tablets for colon targeted drug delivery," Brazilian Journal of Pharmaceutical Sciences, vol. 47, no. 2, pp. 299-311, 2011.

[21] F. García-Ochoa, V. E. Santos, J. A. Casas, and E. Gómez, "Xanthan gum: production, recovery, and properties," Biotechnology Advances, vol. 18, no. 7, pp. 549-579, 2000.

[22] R. Kar, S. Mohapatra, S. Bhanja, D. Das, and B. Barik, "Formulation and in vitro characterization of xanthan gum-based sustained release matrix tables of isosorbide-5-mononitrate," Iranian Journal of Pharmaceutical Research, vol. 9, no. 1, pp. 1319, 2010.

[23] S. Maity and B. Sa, "Development and evaluation of $\mathrm{Ca}^{+2}$ ion cross-linked carboxymethyl xanthan gum tablet prepared by wet granulation technique," AAPS PharmSciTech, vol. 15, no. 4, pp. 920-927, 2014.

[24] S. Maity and B. Sa, "Compression-coated tablet for colon targeting: impact of coating and core materials on drug release," AAPS PharmSciTech, pp. 1-12, 2015.

[25] A. C. Liberman, J. Druker, M. J. Perone, and E. Arzt, "Glucocorticoids in the regulation of transcription factors that control cytokine synthesis," Cytokine and Growth Factor Reviews, vol. 18, no. 1-2, pp. 45-56, 2007.

[26] J. Q. Del Rosso Do, "Combination topical therapy for the treatment of psoriasis," Journal of Drugs in Dermatology, vol. 5, no. 3, pp. 232-234, 2006. 
[27] S. G. Hillier, "Diamonds are forever: the cortisone legacy," Journal of Endocrinology, vol. 195, no. 1, pp. 1-6, 2007.

[28] M. Schwartz and R. Cohen, "Optimizing conventional therapy for inflammatory bowel disease," Current Gastroenterology Reports, vol. 10, no. 6, pp. 585-590, 2008.

[29] K. D. Tripathi, "Hormones and related drugs," in Essential of Medical Pharmacology, section 5, Jaypee Brothers Medical Publishers, New Delhi, India, 5th edition, 2003.

[30] A. K. De, P. Bhattacharya, S. Datta, and A. Mukherjee, "Evaluation of in vivo efficacy and toxicity of prednisolone-loaded hydrogel-based drug delivery device," International Journal of Pharmaceutical Investigation, vol. 3, no. 4, pp. 225-233, 2013.

[31] M. Kusunoki, G. Möeslein, Y. Shoji et al., "Steroid complications in patients with ulcerative colitis," Diseases of the Colon \& Rectum, vol. 35, no. 10, pp. 1003-1009, 1992.

[32] F. Dasankoppa, S. Patwa, H. Sholapur, and G. Arunkumar, "Formulation and characterization of colon specific drug delivery system of prednisolone," Saudi Journal for Health Sciences, vol. 1, no. 3, pp. 143-150, 2012.

[33] The Indian Pharmacopoeia Commission, Indian Pharmacopoeia, 2010.

[34] United States Food and Drug Administration, Bioanalytical Method Validation, 2001.

[35] J. M. Cardot, E. Beyssac, and M. Alric, "In vitro-in vivo correlation: importance of dissolution in IVIVC," Dissolution Technologies, vol. 14, no. 1, pp. 15-19, 2007.

[36] United States Food and Drug Administration, Extended Release Oral Dosage Forms: Development, Evaluation, and Application of In Vitro/In Vivo Correlations, 1997.

[37] N. Yuksel, A. E. Kanik, and T. Baykara, "Comparison of in vitro dissolution profiles by ANOVA-based, model-dependent and independent methods," International Journal of Pharmaceutics, vol. 209, no. 1-2, pp. 57-67, 2000.

[38] T. Ishibashi, H. Hatano, M. Kobayashi, M. Mizobe, and H. Yoshino, "In vivo drug release behavior in dogs from a new colon-targeted delivery system," Journal of Controlled Release, vol. 57, no. 1, pp. 45-53, 1999.

[39] Y. S. R. Krishnaiah, P. V. Raju, B. D. Kumar, V. Satyanarayana, R. S. Karthikeyan, and P. Bhaskar, "Pharmacokinetic evaluation of guar gum-based colon-targeted drug delivery systems of mebendazole in healthy volunteers," Journal of Controlled Release, vol. 88, no. 1, pp. 95-103, 2003.

[40] J. E. Polli, J. R. Crison, and G. L. Amidon, "Novel approach to the analysis of in vitro-in vivo relationships," Journal of Pharmaceutical Sciences, vol. 85, no. 7, pp. 753-760, 1996. 

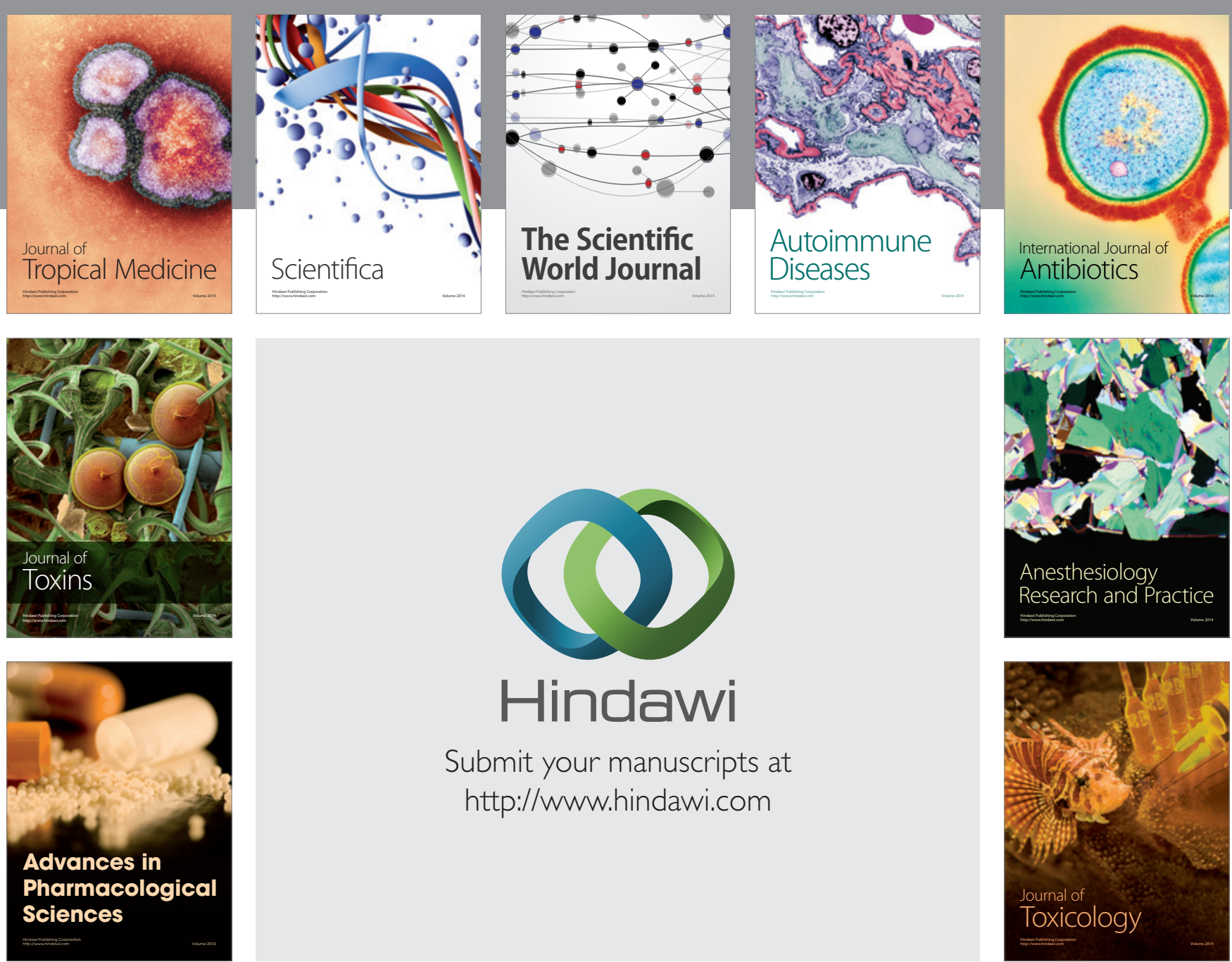

\section{Hindawi}

Submit your manuscripts at

http://www.hindawi.com
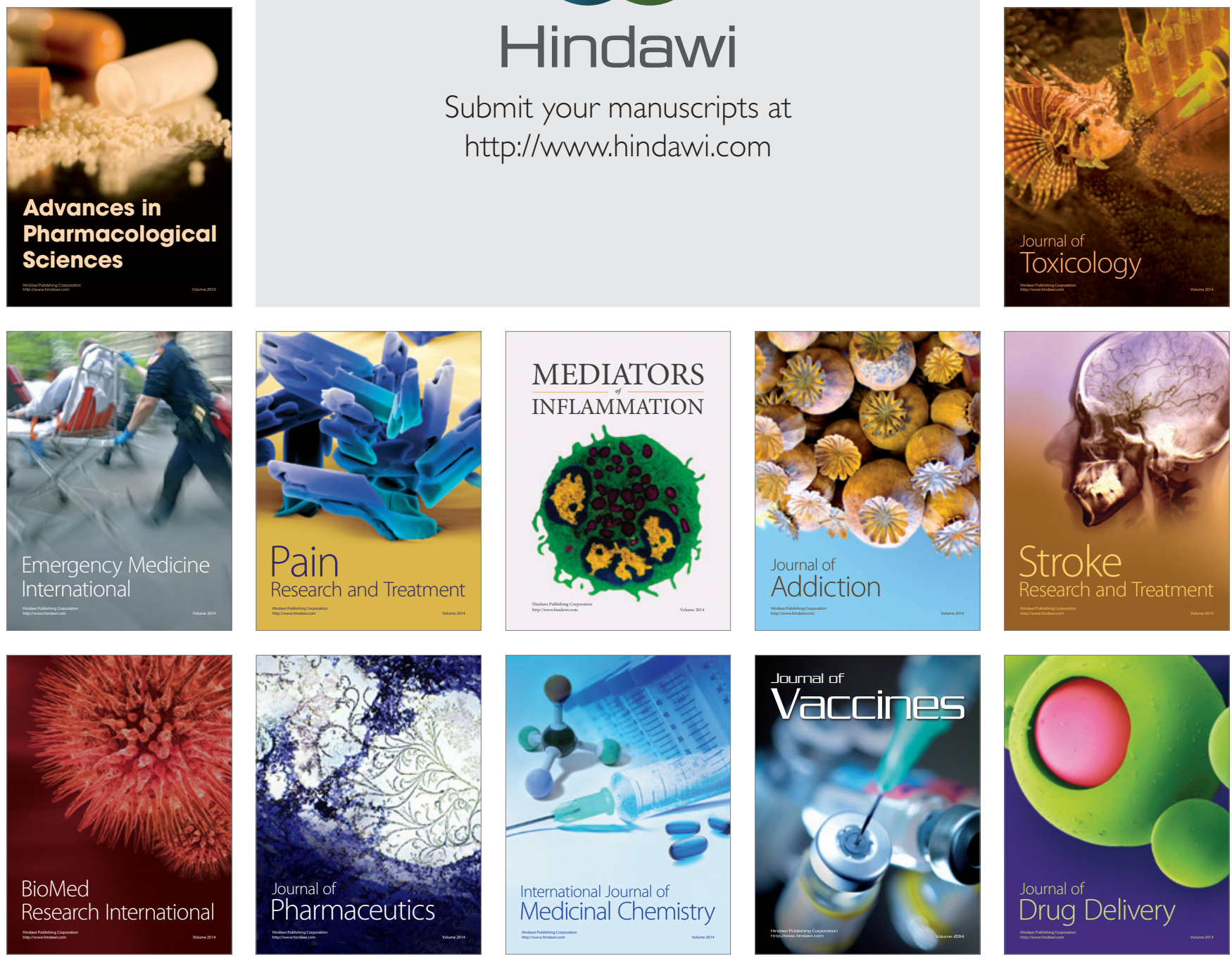